\title{
VIABILIDADE DA UTILIZAÇÃO DE DESCARTES DE PRODUÇÃO DE UVAS SEM SEMENTES PARA ELABORAÇÃO DE PASSAS ${ }^{1}$
}

\author{
NELSON PIRES FELDBERG ${ }^{2}$, RENATA VIEIRADAMOTA ${ }^{3}$, \\ WELSONLIMASIMÕES ${ }^{4}$, MURILLODEALBUQUERQUE REGINA ${ }^{5}$
}

RESUMO- A região do Vale do São Francisco destaca-se na produção de uvas de mesa, com incrementos cada vez maiores na produção de cultivares sem sementes. A fim de evitar perdas e aumentar a renda do produtor, torna-se necessário o desenvolvimento de tecnologias para o aproveitamento do excedente da produção de forma economicamente viável. Considerando-se a dependência do Brasil ao mercado externo em uva-passa, este trabalho teve como objetivo avaliar a viabilidade da elaboração de passas a partir das cultivares sem sementes Sultanina, Catalunha, Superior Seedless e Crimson Seedless produzidas no norte de Minas Gerais. As passas foram analisadas quanto ao teor de umidade, sólidos solúveis totais (SST), acidez total titulável (ATT), pH, açúcares redutores e diâmetros longitudinal e transversal, e os resultados, comparados com o produto chileno adquirido no comércio local. As passas das cultivares produzidas nesta região apresentaram maior tamanho e composição semelhante ao produto importado. As passas de 'Crimson Seedless' apresentaram teor significativamente maior de umidade após 20h de secagem, enquanto Catalunha e Sultanina se destacaram quanto aos teores de SST, ATT e açúcares redutores. Os resultados obtidos indicam que a produção de passas é viável tecnicamente, porém trabalhos complementares são necessários para avaliar a viabilidade econômica deste processo.

Termos para Indexação: uvas apirenas, desidratação, composição.

\section{VIABILITY OF THE UTILIZATION OF SEEDLESS GRAPES DISCARDS FOR RAISIN PRODUCTION}

\begin{abstract}
The São Francisco river valley region in Brazil stands out as table grape producer with increasing rates in seedless grape production. In order to avoid producer's losses and increase their gain, there is a need for the development of technologies to make some profit from the exceeding yield. Considering the Brazilian dependence on the international market for raisin supply, this work aims to evaluate the raisin production from the seedless cultivars Sultanina, Catalunha, Superior Seedless and Crimson Seedless grown in the north region of Minas Gerais, at the São Francisco river valley. Chemical composition of the raisins such as humidity, total soluble solids (TSS), total titrable acidity (TTA), pH and reducing sugars and longitudinal and transversal diameters were evaluated and compared to the imported raisins bought at a local market. Raisins produced in this region showed bigger size and similar composition than the imported ones. Crimson Seedless raisins showed higher humidity after $20 \mathrm{~h}$ of dehydration while Catalunha and Sultanina pointed out in TSS, TTA and reducing sugar amounts. Data show that raisin production is technically feasible, although research is necessary to evaluate the process economically.
\end{abstract}

Index Terms: seedless grapes, dehydration, composition.

Segundo dados da Embrapa (2007), em 2005, foram importados $15.596 .613 \mathrm{~kg}$ de passas com uma evasão de divisas de US\$ 18 milhões. O principal país fornecedor é a Argentina (10 mil t), seguida por Turquia (2 mil t) e Irã (894 mil kg). Esta importação deve-se principalmente à pequena área cultivada com videiras apirenas no País e, por conseqüência, pela baixa oferta deste tipo de uva para a desidratação na forma de passas. Entretanto, nos últimos anos, tem sido verificado um grande aumento no plantio de cultivares apirenas, principalmente nas regiões com tradição em exportação de uvas, devido ao maior valor de mercado deste produto, melhor aceitação por parte dos compradores e ajustes técnicos na parte produtiva que viabilizaram o plantio destas cultivares em climas tropicais (Feldberg, 2006). As principais cultivares, em área plantada e volume de produção, no Vale do Rio São Francisco são: Superior Seedless, Crimson Seedless, Sultanina e Catalunha. O aumento na produção de uvas sem sementes, entretanto, gera excedentes de qualidade inferior, que normalmente são comercializados a um preço baixo, para a produção de vinagre, ou descartados. A utilização do excedente de produção na elaboração de passas pode ser uma alternativa de renda para os produtores de uva de mesa, principalmente no Brasil, classificado em 2003 como

\footnotetext{
${ }^{1}$ (Trabalho 191-07). Recebido em:07-08-2007. Aceito para publicação em: 10-04-2008. Projeto financiado pelo CNPq.

${ }^{2}$ Eng. Agr. Mestre. Bolsista CNPq - Embrapa Transferência de Tecnologia, Avenida André Tosello, 209 - Cidade Universitária, caixa postal 6062, 13083970, Campinas-SP. npfeldberg@yahoo.com.br

${ }^{3}$ Eng. Agr. Dr., Pesquisador Núcleo Tecnológico EPAMIG Uva e Vinho, Caixa Postal 33, 37780-000, Caldas, MG, Brasil, e-mail renata@epamigcaldas.gov.br ${ }^{4}$ Universidade Federal de Viçosa, 36570-000, Viçosa, MG, Brasil, e-mail welsimoes@yahoo.com.br

${ }^{5}$ Eng. Agr. PhD., Pesquisador Núcleo Tecnológico EPAMIG Uva e Vinho, Caixa Postal 33, 37780-000, Caldas, MG, Brasil, e-mail murillo@epamigcaldas.gov.br
} 
segundo maior importador de passas das Américas (OIV, 2003). De maneira geral, a produção de passas exige poucos investimentos em equipamentos, principalmente nas regiões com baixa umidade relativa do ar, além de permitir a adequação da escala de produção à disponibilidade da matéria-prima e conservação do produto em condição ambiente. Albuquerque et. al. (1987) e Vieira (1989) estudaram os processos de desidratação natural ao sol e artificial, respectivamente, para a produção de uvas-passas na região de Petrolina-PE. Entretanto, no primeiro trabalho, os autores utilizaram a cultivar Itália que, por possuir sementes, apresenta mercado restrito e valor inferior para as passas produzidas. No segundo estudo, o autor comenta apenas que as uvas utilizadas deveriam apresentar teor de sólidos solúveis totais em torno de $22^{\circ}$ Brix, sem especificar as cultivares recomendadas para este fim. Por se tratar de um processo pouco explorado no Brasil, há uma carência de informações relacionadas à produção de passas, apesar da demanda elevada por este produto. Desta forma, o objetivo deste trabalho foi desenvolver um estudo preliminar para avaliar algumas características do processo de produção de passas, a partir do excedente de produção de uvas apirenas cultivadas na região norte do Estado de Minas Gerais e comparar a qualidade do produto final com passas importadas, disponíveis no mercado nacional. Foram utilizadas bagas das cultivares Superior Seedless, Catalunha, Sultanina e Crimson Seedless. O vinhedo foi implantado em julho de 2001 sobre o porta-enxerto 'IAC 572 Jales' e conduzido em latada na Fazenda Experimental da Empresa de Pesquisa Agropecuária de Minas Gerais (Epamig), em Mocambinho, distrito de Jaíba-MG, localizado na região norte do Estado de Minas Gerais. Os tratamentos fitossanitários e culturais realizados no parreiral foram os mesmos recomendados por Albuquerque (1996), Leão \& Maia (1998), Pires (1998) e Feldberg (2000), para o cultivo em climas tropicais, incluindo a aplicação de cianamida hidrogenada após a poda para indução da brotação, raleio e aplicação de reguladores de crescimento para aumento do tamanho das bagas e desponte de ramos. Para a elaboração das passas, foram utilizados os cachos sem padrão comercial, que foram deixados no parreiral após a colheita. Os cachos foram colhidos 10 dias após a colheita comercial a fim de proporcionar incremento da qualidade das bagas pelo aumento no teor de sólidos solúveis totais e redução da acidez, e para evitar sobreposição entre o preparo dos cachos para o mercado in natura e a elaboração das passas. As bagas com ausência de podridões foram lavadas em água corrente, mergulhadas em solução de hipoclorito de sódio (50ppm) por 15min e drenadas. Para a caracterização dos frutos in natura, foram determinados os teores de sólidos solúveis totais (SST), acidez total titulável (ATT), $\mathrm{pH}$ e diâmetros longitudinal e transversal das bagas em uma amostragem de 50 bagas de cada cultivar. Os diâmetros longitudinal e transversal das bagas foram medidos com paquímetro manual, e o resultado expresso em milímetros. As determinações químicas foram realizadas no mosto extraído das 50 bagas. Os sólidos solúveis totais foram determinados por leitura direta em refratômetro manual portátil, e o resultado, expresso em ${ }^{\circ}$ Brix. $\mathrm{O} \mathrm{pH}$ do mosto foi determinado em potenciômetro calibrado com padrões $\mathrm{pH}$ 4,0 e 7,0, e a acidez total, expressa em porcentagem de ácido tartárico, foi determinada pela titulação do mosto com $\mathrm{NaOH} 0,1 \mathrm{~N}$, utilizando fenolftaleína como indicador. Para a determinação do teor de umidade, as bagas foram trituradas e colocadas em estufa a $105^{\circ} \mathrm{C}$ até peso constante (Instituto Adolfo Lutz, 1985). As bagas foram desidratadas em estufa com circulação forçada de ar a $70^{\circ} \mathrm{C}$, e as passas para análise foram retiradas após $20 \mathrm{~h}$. Ao mesmo tempo, durante o processo de desidratação, quatro lotes com $50 \mathrm{~g}$ de cada cultivar foram pesados em balança eletrônica para a determinação das curvas de secagem até $48 \mathrm{~h}$. As passas foram armazenadas em sacos plásticos por dois meses e avaliadas quanto aos teores de umidade, pH, ATT, SST, açúcares redutores e diâmetros longitudinal e transversal. Os resultados foram comparados com a composição do produto importado de origem chilena, adquirido no mercado local. Para as análises de $\mathrm{pH}$, SST e ATT, aproximadamente $10 \mathrm{~g}$ de passas homogeneizadas em gral foram extraídas em água a $80^{\circ} \mathrm{C}$ por $2 \mathrm{~h}$. $\mathrm{O}$ volume foi retomado em balão de $100 \mathrm{~mL}$, filtrado em algodão e o eluído utilizado para as determinações. Os açúcares foram extraídos em etanol $80 \%$ a $80^{\circ} \mathrm{C}$ com três lavagens sucessivas de aproximadamente $30 \mathrm{~min}$. Os açúcares redutores foram determinados pelo método de Somogyi-Nelson após a evaporação do álcool (Nelson, 1944; Somogyi, 1945). A prática de manter os cachos sem padrão de mercado no parreiral contribuiu para a melhoria da qualidade das bagas, principalmente quanto ao teor de sólidos solúveis. $\mathrm{Na}$ safra em estudo, os cachos foram colhidos para o mercado in natura com teores médios de sólidos solúveis de $14,4^{\circ}$ Brix, $17,3^{\circ} \mathrm{Brix}, 17,0^{\circ} \mathrm{Brix}$ e $15,8^{\circ} \mathrm{Brix}$, respectivamente, para as cultivares Superior Seedless, Catalunha, Sultanina e Crimson Seedless. A manutenção das bagas no parreiral, por mais dez dias, aumentou de forma significativa os teores de sólidos solúveis em todas as cultivares (Tabela 1). As bagas apresentaram teor de umidade semelhante, cerca de $81 \%$ em média, e foram desidratadas por até $48 \mathrm{~h}$ para a determinação das curvas de secagem. A Figura 1 ilustra as curvas de desidratação observadas para as quatro cultivares.

As curvas de desidratação obtidas para as cultivares apirenas colhidas no norte de Minas Gerais assemelham-se à observada por Doymaz \& Pala (2002) para a cultivar Sultanina sem tratamento das bagas. O tempo de secagem está diretamente relacionado à temperatura e fluxo do ar utilizados na desidratação. Esses autores observaram tempo de desidratação de $18 \mathrm{~h}$ para bagas não-tratadas quando submetidas à temperatura de $70^{\circ} \mathrm{C} \mathrm{e}$ velocidade do ar de $1,2 \mathrm{~m} / \mathrm{s}$. Segundo eles, o tempo de desidratação aumentou para $48 \mathrm{~h}$ quando a temperatura de secagem foi reduzida em $10^{\circ} \mathrm{C}$. Em trabalho realizado por Di Matteo et al. (2000), foram necessárias $90 \mathrm{~h}$ para reduzir a umidade das bagas de $84 \%$ para $20 \%$ em estufa a $50^{\circ} \mathrm{C}$ e velocidade do ar de $0,5 \mathrm{~m} / \mathrm{s}$. De maneira geral, a composição química das passas, elaboradas a partir das quatro cultivares apirenas cultivadas no norte de Minas Gerais, assemelha-se à composição química da passa importada de origem chilena, adquirida no mercado local (Tabela 2). As cultivares Catalunha e Sultanina destacaram-se quanto aos teores de SST, ATT e açúcares redutores, o que já era esperado devido às características observadas na uva in natura. Estas cultivares apresentaram relação SST/ATT em torno de 21,5, enquanto as demais cultivares e o produto importado 
apresentaram relação média de 31,8 . As passas elaboradas neste trabalho apresentaram, em média, diâmetro longitudinal $1,7 \mathrm{vez}$ maior do que o produto importado e transversal 1,4 vez maior (Tabela 3), com destaque para a cultivar Superior Seedless. Possivelmente, as bagas utilizadas para a produção das passas importadas eram provenientes de cachos não-tratados com reguladores de crescimento e, por isso, tenham apresentado tamanho bastante inferior. Este estudo preliminar indica que a produção de passas a partir dos cachos fora de padrão de mercado ou até mesmo do excedente da produção é uma opção tecnicamente viável, tanto no que diz respeito à rapidez e facilidade do processo de produção, quanto na qualidade final do produto obtido. Entretanto, faz-se necessária a condução de estudos mais detalhados para averiguação da viabilidade econômica do processo.

TABELA 1 - Características físico-químicas de 50 bagas in natura das cultivares Superior Seedless, Catalunha, Crimson Seedless e Sultanina cultivadas no norte de Minas Gerais, na safra de 2005.

\begin{tabular}{ccccc}
\hline Cultivar/ & Superior Seedless & Catalunha & Crimson Seedless & Sultanina \\
Data da colheita & $20-06-05$ & $20-06-05$ & $19-07-05$ & $20-06-05$ \\
\hline pH & 3,85 & 3,41 & 3,53 & 3,54 \\
STT( ${ }^{B}$ Brix $)$ & 15,8 & 20,8 & 19,2 & 18,2 \\
ATT(\% ác. tartárico) & 3,3 & 7,2 & 5,8 & 7,3 \\
Diâmetro longitudinal $(\mathrm{mm})$ & 26,8 & 26,1 & 28,2 & 24,1 \\
Diâmetro transversal $(\mathrm{mm})$ & 19,4 & 16,9 & 17,8 & 16,4 \\
Peso $/$ baga $(\mathrm{g})$ & 6,4 & 5,0 & 5,6 & 4,2 \\
Umidade $(\%)$ & 82,7 & 80,5 & 80,4 & 81,7 \\
\hline
\end{tabular}

TABELA 2 - Composição química de passas produzidas a partir de cultivares apirenas cultivadas no norte de Minas Gerais e do produto importado, 2005.

\begin{tabular}{lccccc}
\hline \multicolumn{1}{c}{ Cultivar } & $\mathrm{pH}$ & $\begin{array}{c}\text { ATT (\% ácido } \\
\text { tartárico) }\end{array}$ & $\begin{array}{c}\text { SST } \\
\left({ }^{B} \text { Brix) }\right.\end{array}$ & $\begin{array}{c}\text { Relação } \\
\text { } \text { Brix/acidez }\end{array}$ & $\begin{array}{c}\text { Aḉćares } \\
\text { Redutores }(\%)\end{array}$ \\
\hline Passa importada & $3,81 \pm 0,04 \mathrm{ab}$ & $2,21 \pm 0,03 \mathrm{c}$ & $70,95 \pm 1,31 \mathrm{~b}$ & $32,06 \pm 0,34 \mathrm{a}$ & $57,46 \pm 18,76 \mathrm{c}$ \\
Superior Seedless & $3,86 \pm 0,01 \mathrm{a}$ & $2,32 \pm 0,02 \mathrm{c}$ & $72,80 \pm 0,77 \mathrm{~b}$ & $31,37 \pm 0,55 \mathrm{a}$ & $59,17 \pm 3,27 \mathrm{bc}$ \\
Catalunha & $3,58 \pm 0,02 \mathrm{~d}$ & $3,78 \pm 0,08 \mathrm{a}$ & $77,00 \pm 0,48 \mathrm{a}$ & $20,37 \pm 0,53 \mathrm{c}$ & $61,70 \pm 20,73 \mathrm{ab}$ \\
Crimson Seedless & $3,79 \pm 0 \mathrm{~b}$ & $1,95 \pm 0,02 \mathrm{~d}$ & $61,34 \pm 0,83 \mathrm{c}$ & $31,38 \pm 0,68 \mathrm{a}$ & $52,95 \pm 14,02 \mathrm{~d}$ \\
Sultanina & $3,64 \pm 0,02 \mathrm{c}$ & $3,39 \pm 0,11 \mathrm{~b}$ & $77,01 \pm 0,69 \mathrm{a}$ & $22,72 \pm 0,62 \mathrm{~b}$ & $63,99 \pm 8,59 \mathrm{a}$ \\
\hline
\end{tabular}

Médias representam três repetições analíticas \pm desvio-padrão.

Médias seguidas de letras diferentes na mesma coluna diferem significativamente, pelo Teste de Tukey, ao nível de 5\% de probabilidade.

TABELA 3 - Composição física de passas produzidas a partir de cultivares apirenas cultivadas no norte de Minas Gerais e do produto importado, 2005.

\begin{tabular}{lcccc}
\hline \multicolumn{1}{c}{ Cultivar } & $\begin{array}{c}\text { Umidade } \\
(\%)\end{array}$ & $\begin{array}{c}\text { Diâmetro longitudinal } \\
(\mathrm{mm})\end{array}$ & $\begin{array}{c}\text { Diâmetro transversal } \\
(\mathrm{mm})\end{array}$ & $\begin{array}{c}\text { Relacão diâmetros } \\
\text { longitudinal/transversal }\end{array}$ \\
\hline Passa importada & $26,31 \pm 1,97 \mathrm{~b}$ & $12,90 \pm 2,34 \mathrm{c}$ & $8,29 \pm 2,10 \mathrm{c}$ & $1,65 \pm 0,59 \mathrm{c}$ \\
Superior Seedless & $25,67 \pm 1,24 \mathrm{~b}$ & $23,56 \pm 1,75 \mathrm{a}$ & $13,75 \pm 1,57 \mathrm{a}$ & $1,74 \pm 0,24 \mathrm{bc}$ \\
Catalunha & $25,31 \pm 0,66 \mathrm{~b}$ & $21,13 \pm 1,87 \mathrm{~b}$ & $10,58 \pm 0,93 \mathrm{~b}$ & $2,01 \pm 0,26 \mathrm{ab}$ \\
Crimson Seedless & $38,70 \pm 1,38 \mathrm{a}$ & $22,09 \pm 1,95 \mathrm{ab}$ & $10,57 \pm 0,84 \mathrm{~b}$ & $2,10 \pm 0,20 \mathrm{a}$ \\
Sultanina & $24,03 \pm 0,51 \mathrm{~b}$ & $22,14 \pm 2,22 \mathrm{ab}$ & $10,81 \pm 1,36 \mathrm{~b}$ & $2,09 \pm 0,38 \mathrm{a}$ \\
\hline
\end{tabular}

Médias representam três repetições analíticas \pm desvio-padrão.

Médias seguidas de letras diferentes na mesma coluna diferem significativamente, pelo Teste de Tukey, ao nível de 5\% de probabilidade.

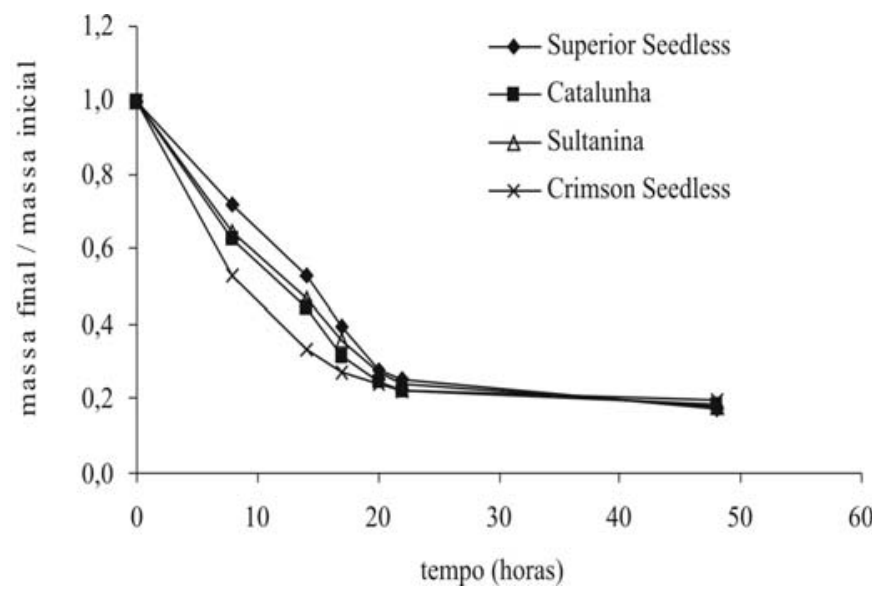

FIGURA 1- Curvas de desidratação de quatro cultivares de uvas apirenas secas a $70^{\circ} \mathrm{C}$ em estufa ventilada, 2005.

\section{REFERÊNCIAS}

ALBUQUERQUE, T. C. S. de, ALbUQUERQUE, J. A. S. de, VIEIRA, S. M. do N. S. Processamento de uvas-passa na região semi-árida do Nordeste. Petrolina: EMBRAPA CPATSA, 1987. 4p. (Comunicado Técnico, 21).

ALBUQUERQUE, T. C. S. de. Uvas para exportação: aspectos técnicos da produção. Brasília: EMBRAPA-SPI, 1996. 53p. (Série Publicações Técnicas FRUPEX, 25).

DIMATTEO, M., CINQUANTA,L., GALIERO, G., CRESCITELLI, S. Effect of a novel physical pretreatment process on the drying kinetics of seedless grapes. Journal of Food Engineering, Kidligton, v.46, n.2, p.83-89, 2000.

DOYMAZ, I., PALA, M. The effects of dipping pretreatments on air-drying rates of the seedless grapes. Journal of Food Engineering, Kidlington, v. 52, n.4, p. 413-417, 2002.

EMBRAPA. Dados da vitivinicultura: importação de uvas secas (passas). Disponível em: <http://www.cnpuv.embrapa.br/ servicos/vitivinicultura/importacao/passas_2005.html > Acesso em: 24 abr. 2007.

FELDBERG, N.P. Relatório final do estágio curricular optativo do curso de agronomia, realizado junto às fazendas do grupo Carrefour, Petrolina-PE. Jaboticabal: FCAV/UNESP, 2000. 37p.

FELDBERG, N. P. Introdução e avaliação agronômica de variedades apirênicas de videira no Norte de Minas Gerais. 2006. 131 f. Dissertação (Mestrado em Fitotecnia) - Universidade Federal de Lavras, Lavras, 2006.

INSTITUTO ADOLFO LUTZ. Normas analíticas do Instituto Adolfo Lutz: métodos químicos e físicos para análise de alimentos. 3.ed. São Paulo: Inst. Adolfo Lutz, 1985. v.1, 533p. 
LEÃO, P.C. de S.; MAIA, J.D.G. Aspectos culturais em viticultura tropical: uva de mesa. Informe Agropecuário, Belo Horizonte, v.19, n. 194, p. 34-39, 1998.

NELSON, N.A. A photometric adaptation of the Somogyi method for the determination of glucose. Journal of Biological Chemistry, Baltimore, v.153, n.2, p.375-380, 1944.

OIV - ORGANISATION INTERNATIONALE DE LA VIGNE ET DU VIN. World Statistics 2003. Paris. 151p. supl. do Bulletin de L'OIV.
PIRES, E.J.P. Emprego de reguladores de crescimento em viticultura tropical. Informe Agropecuário, Belo Horizonte, v.19, n. 194, p. 40-3, 1998.

SOMOGYI, M. Determination of blood sugar. Journal of Biological Chemistry, Baltimore, v.160, n.1, p. 69-73, 1945.

VIEIRA, S. M. do N. S. Produção de passas através da desidratação artificial na região semi-árida brasileira. Petrolina: EMBRAPA CPATSA, 1989. 2p. (Comunicado Técnico, 38). 